\title{
Quantitative analysis of the MRI features in the differentiation of benign, borderline, and malignant epithelial ovarian tumors
}

\author{
Fuxia Xiao ${ }^{\dagger}$, Lin Zhang ${ }^{\dagger}$, Sihua Yang, Kun Peng, Ting Hua and Guangyu Tang*
}

\begin{abstract}
Objective: This study aims to investigate the value of the quantitative indicators of MRI in the differential diagnoses of benign, borderline, and malignant epithelial ovarian tumors (EOTs).

Materials and methods: The study population comprised 477 women with 513 masses who underwent MRI and operation, including benign EOTs (BeEOTs), borderline EOTs (BEOTs), and malignant EOTs (MEOTs). The clinical information and MRI findings of the three groups were compared. Then, multivariate logistic regression analysis was performed to find the independent diagnostic factors. The receiver operating characteristic (ROC) curves were also used to evaluate the diagnostic performance of the quantitative indicators of MRI and clinical information in differentiating BeEOTs from BEOTs or differentiating BEOTs from MEOTs.

Results: The MEOTs likely involved postmenopausal women and showed higher CA-125, HE4 levels, ROMA indices, peritoneal carcinomatosis and bilateral involvement than BeEOTs and BEOTs. Compared with BEOTs, BeEOTs and MEOTs appeared to be more frequently oligocystic $(P<0.001)$. BeEOTs were more likely to show mild enhancement $(P<0.001)$ and less ascites $(P=0.003)$ than BEOTs and MEOTs. In the quantitative indicators of MRI, BeEOTs usually showed thin-walled cysts and no solid component. BEOTs displayed irregular thickened wall and less solid portion. MEOTs were more frequently characterized as solid or predominantly solid mass $(P<0.001)$ than BeEOTs and BEOTs. The multivariate logistic regression analysis showed that volume of the solid portion $(P=0.006)$, maximum diameter of the solid portion $(P=0.038)$, enhancement degrees $(P<0.001)$, and peritoneal carcinomatosis $(P=0.011)$ were significant indicators for the differential diagnosis of the three groups. The area under the curves (AUCS) of above indicators and combination of four image features except peritoneal carcinomatosis for the differential diagnosis of BeEOTs and BEOTs, BEOTs and MEOTs ranged from 0.74 to $0.85,0.58$ to 0.79 , respectively.
\end{abstract}

Conclusion: In this study, the characteristics of MRI can provide objective quantitative indicators for the accurate imaging diagnosis of three categories of EOTs and are helpful for clinical decision-making. Among these MRI characteristics, the volume, diameter, and enhancement degrees of the solid portion showed good diagnostic performance.

Keywords: Ovarian neoplasms, Magnetic resonance imaging, Differential diagnosis

*Correspondence: tgy17@126.com

${ }^{\dagger}$ Fuxia Xiao and Lin Zhang contributed equally to this study.

${ }^{\dagger}$ Fuxia Xiao and Lin Zhang should be considered as co-first authors.

Department of Radiology, Shanghai Tenth People's Hospital of Tongji

University, 301 Middle Yanchang Road, Shanghai 200072, China

\begin{abstract}
Introduction
Epithelial ovarian tumor (EOT) is the most common type in the classification of ovarian tumors and are categorized as benign (BeEOTs), borderline (BEOTs), and malignant (MEOTs) on the basis of histological results. Ovarian tumors remain the first indication for gynecologic surgery $[1,2]$. Laparoscopic tumor exfoliation or
\end{abstract} original author(s) and the source, provide a link to the Creative Commons licence, and indicate if changes were made. The images or other third party material in this article are included in the article's Creative Commons licence, unless indicated otherwise in a credit line to the material. If material is not included in the article's Creative Commons licence and your intended use is not permitted by statutory regulation or exceeds the permitted use, you will need to obtain permission directly from the copyright holder. To view a copy of this licence, visit http://creativecommons.org/licenses/by/4.0/. The Creative Commons Public Domain Dedication waiver (http://creativeco mmons.org/publicdomain/zero/1.0/) applies to the data made available in this article, unless otherwise stated in a credit line to the data. 
unilateral ovariectomy can be performed if the mass is a small BeEOT [3-6]. Young patients with BEOTs can undergo conservative surgery to preserve fertility or maintain ovarian function [7-10], whereas patients with MEOTs require the radical resection of tumors, followed by adjuvant chemotherapy [10-14]. Thus, the accurate diagnosis of the preoperative subtype of EOTs is important for the patient's therapeutic schedule and prognosis. This study aims to analyze the quantitative indicators of magnetic resonance (MR) image for the accurate diagnosis of EOTs and explore the weight of those features in the differential diagnoses of the three types of EOTs through multiple regression analysis.

\section{Material and methods}

\section{Patients}

All patients with EOTs who underwent preoperative MRI from our picture archiving and communication system (PACS) database and had pathological results between January 1, 2009 and August 31, 2018 were retrospectively recruited. The subjects consisted of 477 patients with 513 EOTs. A total of 441 women had one mass, and 36 women had two masses. The histological subtypes of EOTs are shown in Table 2. The population characteristics and biochemical examinations are shown in Table 3. The recruit tumors were categorized into the BeEOTs, BEOTs, and MEOTs groups on the basis of the pathological results. This retrospective study was approved by the institutional review board with the waiver of the informed consent.

\section{MRI technique}

The MR images were acquired using the 3.0-T MR imaging unit (Magnetom Verio, Siemens Medical Solutions, Germany) by employing a pelvic phased-array coil. The following imaging sequences were performed: transverse nonfat-suppressed T2-weighted turbo spinecho sequences (repetition time [TR], $4050 \mathrm{~ms}$; echo time [TE], $84 \mathrm{~ms}$; section thickness, $4 \mathrm{~mm}$; field of view (FOV), $325 \mathrm{~mm}$; matrix, $384 \times 256$; and number of excitations [NEX] 2), transverse nonfat-suppressed T1-weighted gradient-echo sequences (TR, $550 \mathrm{~ms}$; TE, $13 \mathrm{~ms}$; section thickness, $4 \mathrm{~mm}$; FOV, $325 \mathrm{~mm}$; matrix, $384 \times 256$; and NEX, 2), sagittal fat-suppressed T2-weighted turbo spin-echo sequences, and coronal nonfat-suppressed T2-weighted turbo spin-echo sequences. Then, dynamic contrast-enhanced MRI (DCE-MRI) with 3D fat-suppressed T1-weighted interpolated spoiled gradient-echo sequence with volumetric interpolated breath-hold examination was performed in the transverse, sagittal, and coronal planes at scanning delay times of 40 and $120 \mathrm{~s}$ after the bolus injection $(2.5 \mathrm{~mL} / \mathrm{s})$ of gadopentetate dimeglumine
(0.5 mol/L, Beijing Beilu Pharmaceutical Company) at a dose of $0.1 \mathrm{mmol} / \mathrm{kg}$, followed by $50 \mathrm{~mL}$ saline flush through the antecubital vein.

\section{MR images analysis}

Two radiologists who were blinded to the pathological results independently reviewed the MR images and collected the clinical information of the patients. The characteristics of MRI include volume of tumor, maximum diameter of tumor, septum thickness, volume of solid portion, volume ratio of solid portion, maximum diameter of solid portion, maximum diameter ratio of solid portion, number of cysts, peritoneal carcinomatosis, ascites, bilateral involvemen. The degree of tumor enhancement was divided into three categories as follows: mild enhancement (less than), moderate (equal than) and prominent enhancement (greater than), compared with that of uterine myometrium on the delayed enhancement images of MRI. The criteria of MRI were elaborated on the basis of several previously published terms (Table 1).

\section{Statistical analysis}

Statistical analysis was performed using the SPSS 20.0 (SPSS, Inc., Chicago, IL, USA). Continuous variables, such as patient's age and serum carbohydrate antigen 125 (CA-125) level, were expressed as mean \pm standard deviation. The kappa and intraclass correlation (ICCs) coefficients were calculated to assess the interobserver agreement between the two readers for imaging parameter analysis. A kappa value of $0.00-0.20,0.21-0.40$, $0.41-0.60,0.61-0.80$, and $0.81-1.00$ indicated slight, fair, moderate, substantial, and almost perfect agreement, respectively [17]. An ICC value of $0.00-0.10$ indicated virtually no agreement, and ICC values of $0.11-0.40$, $0.41-0.60,0.61-0.80$, and $0.81-1.00$ indicated slight, fair, moderate, and substantial agreement, respectively [18]. In order to identify significant differences in MR imaging parameters, population characteristics and biochemical examinations, the Kruskal-Wallis test was used for continuous variables and categorical data among three groups. Multivariate logistic regression analysis was performed using all qualitative and quantitative variables to find the independent diagnostic factors. The receiver operating characteristic (ROC) curves were used to evaluate the diagnostic performance of MR characteristics and clinical information in differentiating BeEOTs, BEOTs, and MEOTs. ROC analysis was performed using the Medcalc version 15.6 (MedCalc Software, Mariakerke, Belgium). A $P$ value $<0.05$ was considered statistically significant. 
Table 1 Definition of MRI findings

\begin{tabular}{|c|c|c|c|}
\hline Term & Reference & Definition & Measurement standard \\
\hline Septum thickness & Timmerman et al. [15]. & $\begin{array}{l}\text { Thickness of septum or septa within a } \\
\text { cystic tissue }\end{array}$ & $\begin{array}{l}\text { If the septum is irregular, select the thick- } \\
\text { est focal area. }\end{array}$ \\
\hline Volume of tumor & GAO Mei-chun [16] & - & $\begin{array}{l}\text { The volume of tumors was estimated in } \\
\text { PACS by measuring the area of the tumor } \\
\text { on contiguous } 3.0 \mathrm{~mm} \text { thick transverse } \\
\text { slices throughout the whole length of } \\
\text { tumor by using manually drawn bounda- } \\
\text { ries. The area was generated automati- } \\
\text { cally, and the volume of tumors were cal- } \\
\text { culated by multiplying the slice thickness } \\
\text { with the sum of the tumor cross-sectional } \\
\text { area (Cavalieri's principle) }\end{array}$ \\
\hline Volume of solid portion & Timmerman et al. [15]. & $\begin{array}{l}\text { As defined by the IOTA group, at MR } \\
\text { imaging, solid tissue enhances after } \\
\text { gadolinium chelate injection. Therefore, } \\
\text { the solid tissue includes vegetation. }\end{array}$ & $\begin{array}{l}\text { The method of measurement was the } \\
\text { same as that of the "volume of tumor". }\end{array}$ \\
\hline Volume ratio of solid portion & & $\begin{array}{l}\text { The proportion of solid components in } \\
\text { the total tumorous volume }\end{array}$ & $\begin{array}{l}=\text { Volume of solid portion/Volume of } \\
\text { tumor }\end{array}$ \\
\hline Maximum diameter of tumor & & $\begin{array}{l}\text { The diameter of the largest level of the } \\
\text { tumor }\end{array}$ & - \\
\hline Maximum diameter of solid portion & & $\begin{array}{l}\text { The diameter of the largest level of the } \\
\text { tumorous solid portion }\end{array}$ & - \\
\hline $\begin{array}{l}\text { Maximum diameter ratio of solid por- } \\
\text { tion }\end{array}$ & & $\begin{array}{l}\text { The ratio of the maximum diameter of } \\
\text { solid portion and the maximum diam- } \\
\text { eter of tumor }\end{array}$ & $\begin{array}{l}\text { =Maximum diameter of solid portion/ } \\
\text { Maximum diameter of tumor }\end{array}$ \\
\hline
\end{tabular}

Table 2 The distribution of histological subtypes of EOTs

\begin{tabular}{llll}
\hline & Benign $(\boldsymbol{n}=\mathbf{3 3 0})$ & Borderline $(\boldsymbol{n}=\mathbf{4 9})$ & Malignant $(\boldsymbol{n}=\mathbf{9 8})$ \\
\hline Serous tumours & $161(48.79)$ & $27(55.10)$ & $39(39.79)$ \\
Mucinous tumors & $144(43.64)$ & $11(22.45)$ & $21(21.43)$ \\
Endometrioid tumors & $2(0.61)$ & $1(2.04)$ & $19(19.39)$ \\
Clear cell tumors & $0(0)$ & $2(4.08)$ & $18(18.37)$ \\
Brenner tumours & $5(1.51)$ & $1(2.04)$ & $1(1.02)$ \\
Serous-mucinous tumors & $18(5.45)$ & $7(14.29)$ & $0(0)$ \\
\hline
\end{tabular}

The number in parenthesis is the percentage

Table 3 Population clinical characteristics and biochemical examinations of blood

\begin{tabular}{|c|c|c|c|c|}
\hline & $\begin{array}{l}\text { BeEOTs }\left(n=330, n^{*}=347\right. \\
\left.n^{*}=305\right)\end{array}$ & $\begin{array}{l}\text { BEOTs }\left(n=49, n^{*}=50,\right. \\
\left.n^{*}=48\right)\end{array}$ & $\begin{array}{l}\text { MEOTs }\left(n=98, n^{*}=116\right. \\
\left.n^{*}=109\right)\end{array}$ & $P$ value \\
\hline Age & $48.20 \pm 13.04$ & $47.61 \pm 17.14$ & $56.44 \pm 7.79$ & 0.001 \\
\hline Postmenopausal & & & & 0.002 \\
\hline No & $148(44.85)$ & $26(53.06)$ & $25(25.51)$ & \\
\hline Yes & 182(55.15) & $23(46.94)$ & 73(74.49) & \\
\hline CA-125 & $19.92 \pm 29.00$ & $89.82 \pm 191.24$ & $523.92 \pm 835.60$ & $<0.001$ \\
\hline HE 4 & $51.92 \pm 16.91$ & $100.12 \pm 124.28$ & $260.23 \pm 239.23$ & $<0.001$ \\
\hline Premenopausal ROMA index & $9.23 \pm 6.14$ & $9.36 \pm 5.77$ & $47.81 \pm 35.52$ & $<0.001$ \\
\hline Postmenopausal ROMA index & $11.08 \pm 3.68$ & $20.06 \pm 15.98$ & $57.95 \pm 30.22$ & 0.001 \\
\hline
\end{tabular}

The case number of BeEOTs $(n)$ is 330 (unilateral 313, bilateral 17) with 347 tumors $\left(n^{*}\right)$. The number of tumors with contrast enhanced MR imaging $\left(n^{*}\right)$ is 305 The case number of BEOTs $(n)$ is 49 (unilateral 48 , bilateral 1) with 50 tumors $\left(n^{*}\right)$. The number of tumors with contrast enhanced MR imaging ( $\left.n^{*}\right)$ is 48 The case number of MEOTs(n) is 98 (unilateral 80 , bilateral 18) with 116 tumors $\left(n^{*}\right)$. The number of tumors with contrast enhanced MR imaging $\left(n^{*}\right)$ is 109 The number in parenthesis is the percentage 


\section{Results}

\section{Histological subtypes of EOTs}

Table 2 shows the distribution of pathological subtypes of EOTs include serous tumours, mucinous tumors, endometrioid tumors, clear cell tumors, brenner tumours, serous-mucinous tumors. Among these histological subtypes, serous tumours and mucinous tumors accounted for the majority of all subtypes (total percentage was $84.49 \%$ ). Meanwhile, there was a high proportion of serous tumours and mucinous tumors in each group (92.43, 77.55\%,61.22\%, respectively).

\section{Clinical evaluation}

The population characteristics and biochemical examinations of the blood samples of 477 patients with 513 ovarian masses are demonstrated in Table 3 . Their mean age was $52.36 \pm 12.71$ (range 18-86) years. A total of 208 (43.61\%) women were premenopausal, and 269 (56.39\%) were postmenopausal. Thirty-six (7.55\%) patients had bilateral tumors, and 441 (92.45\%) patients had unilateral tumors. The significant differences were obtained for all indicators, including age, postmenopause, CA-125 level, human epididymis protein 4 (HE4), and premenopausal and postmenopausal risk of ovarian malignancy algorithm (ROMA) indices.

\section{Interobserver agreement}

For all MR imaging variables, the interobserver agreement was good (ICC $=0.899-0.999$, kappa $=0.932-$ 0.978; Table 4).

\section{MR image analysis}

Table 5 shows the characteristics of the MR imaging findings in EOTs among benign, borderline, and malignant lesions by using univariate analysis. Compared with BEOTs, BeEOTs and MEOTs had less cysts (23/50, 46\% vs $311 / 347,89.63 \%$ and $88 / 116,75.86 \%, P<0.001)$. Most BeEOTs had mild enhancement (290/305, 95.08\% vs

Table 4 Interobserver agreement of MR imaging variables

\begin{tabular}{lll}
\hline MR Imaging Variables & K value & ICC(95\%Cl) \\
\hline Volume of tumor & - & $0.988(0.985-0.991)$ \\
Volume of solid portion & - & $0.899(0.870-0.922)$ \\
Volume ratio of solid portion & - & $0.982(0.976-0.986)$ \\
Maximum diameter of tumor & - & $0.988(0.985-0.991)$ \\
Maximum diameter of solid portion & - & $0.995(0.994-0.997)$ \\
Maximum diameter ratio of solid portion & - & $0.999(0.998-0.999)$ \\
Enhancement degrees & 0.965 & - \\
Ascites & 0.978 & - \\
Peritoneal carcinomatosis & 0.932 & - \\
\hline
\end{tabular}

$16 / 48,33.33 \%$ and $9 / 109,8.26 \%, P<0.001)$ and less frequent ascites $(75 / 330,22.72 \%$ vs $27 / 49,55.10 \%$ and $65 / 98$, $66.33 \%, P=0.003)$ than BEOTs and MEOTs. Peritoneal carcinomatosis was found in 24.49\% (24/98) of MEOTs, $0 \%$ of BeEOTs, and $2.04 \%(1 / 49)$ of BEOTs $(P<0.001)$, and bilateral involvement were more frequent in MEOTs $(18.37 \%, 18 / 98)$ than in BeEOTs $(6.06 \%, 20 / 330)$ and BEOTs $(2.04 \%, 1 / 49)(P=0.002$, Figs. 1,2 and 3$)$. In quantitative MR imaging descriptors, BeEOTs usually showed thin-walled cysts and no solid component, but BEOTs often displayed irregular thickened walls and small amount of solid portion. MEOTs were more frequently characterized as completely solid or predominantly solid mass $(P<0.001$, Figs. 1,2 and 3$)$. No statistical difference was found among the three groups in terms of volume of tumor and maximum diameter of tumor $(P=0.058$, $P=0.055$, respectively).

Multivariate logistic regression analysis was performed to obtain independent differential diagnostic factors. Results are shown in Table 6 . The outcome revealed that volume of solid portion $(P=0.006)$, maximum diameter of solid portion $(P=0.038)$, enhancement degrees $(P<0.001)$, and peritoneal carcinomatosis $(P=0.011)$ were significant indicators for differentiate diagnosis of the three groups.

Then, the diagnostic performance of $\mathrm{MR}$ imaging parameters, including volume of solid portion, maximum diameter of solid portion, enhancement degrees, peritoneal carcinomatosis, and their combination were assessed and compared using ROC analyses to differentiate two groups.

The area under the curve (AUC), sensitivity, specificity, positive predictive value (PPV) and negative predictive value (NPV) of this multivariate logistic regression model are shown in Table 7 and Fig. 4. In comparing BeEOTs and BEOTs, the image features of volume of solid portion, maximum diameter of solid portion, enhancement degrees, and the combination of four image features revealed moderate diagnostic value $(0.74,0.74,0.8$, 0.85 , respectively), whereas peritoneal carcinomatosis showed low diagnostic value (0.51). Moreover, the above indicators except enhancement degrees (0.58) and peritoneal carcinomatosis (0.61) demonstrated moderate diagnostic value in BEOTs and MEOTs $(0.78,0.76,0.79$, respectively).

\section{Discussion}

Adnexal masses, in general, are first found and evaluated using ultrasonography [19]. Nevertheless, in a prospective randomized trial in 2010, a consensus conference of the Society of Radiologists in Ultrasound proposed that establishing structured standards for adnexal cysts is needed [20]. To date, numerous scoring systems for 
Table 5 The difference of MRI parameters among three groups of EOTs

\begin{tabular}{|c|c|c|c|c|}
\hline & $\begin{array}{l}\text { BeEOTs }\left(n=330, n^{*}=347\right. \\
\left.n^{*}=305\right)\end{array}$ & $\begin{array}{l}\text { BEOTs }\left(n=49, n^{*}=50\right. \\
\left.n^{*}=48\right)\end{array}$ & $\begin{array}{l}\text { MEOTs }\left(n=98, n^{*}=116\right. \\
\left.n^{*}=109\right)\end{array}$ & $P$ value \\
\hline Septum thickness & $0.24 \pm 0.11$ & $0.53 \pm 0.41$ & $0.77 \pm 0.34$ & $<0.001$ \\
\hline Volume of tumor & $483.30 \pm 883.11$ & $1106.15 \pm 2000.28$ & $412.88 \pm 674.36$ & 0.058 \\
\hline Volume of solid portion & $0.00 \pm 0.00$ & $57.23 \pm 163.74$ & $79.63 \pm 120.08$ & $<0.001$ \\
\hline Volume ratio of solid portion & $0.00 \pm 0.00$ & $9.58 \pm 19.98$ & $43.36 \pm 37.49$ & $<0.001$ \\
\hline Maximum diameter of tumor & $9.02 \pm 6.19$ & $12.44 \pm 7.63$ & $9.47 \pm 4.50$ & 0.055 \\
\hline Maximum diameter of solid portion & $0.00 \pm 0.00$ & $2.52 \pm 3.60$ & $5.25 \pm 3.03$ & $<0.001$ \\
\hline Maximum diameter ratio of solid portion & $0.00 \pm 0.00$ & $22.84 \pm 30.11$ & $62.56 \pm 33.19$ & $<0.001$ \\
\hline Bilateral involvement & & & & 0.002 \\
\hline No & $310(93.94)$ & 48(97.96) & $80(81.63)$ & \\
\hline Yes & $20(6.06)$ & $1(2.04)$ & 18(18.37) & \\
\hline Number of cysts & & & & $<0.001$ \\
\hline$<5$ & $311(89.63)$ & 23(46.00) & $88(75.86)$ & \\
\hline $5-10$ & $15(4.32)$ & $3(6.00)$ & $13(11.21)$ & \\
\hline$>10$ & $21(6.05)$ & $24(48.00)$ & $15(12.93)$ & \\
\hline Enhancement degrees & & & & $<0.001$ \\
\hline Mild & 290(95.08) & 16(33.33) & $9(8.26)$ & \\
\hline Moderate & $0(0)$ & $4(8.33)$ & $29(26.60)$ & \\
\hline Prominent & $15(4.92)$ & $28(58.34)$ & $71(65.14)$ & \\
\hline Ascites & & & & 0.003 \\
\hline No & $255(77.27)$ & $22(44.90)$ & $33(33.67)$ & \\
\hline Yes & $75(22.72)$ & $27(55.10)$ & $65(66.33)$ & \\
\hline Peritoneal carcinomatosis & & & & $<0.001$ \\
\hline No & $330(100)$ & 48(97.96) & $74(75.51)$ & \\
\hline Yes & $0(0)$ & $1(2.04)$ & $24(24.49)$ & \\
\hline
\end{tabular}

preoperative mass discrimination have been developed [21]. Fernando Amor et al. [22, 23] proposed the Gynecologic Imaging Reporting and Data System (GI-RADS) to guide every imaging modality in describing and categorizing ovarian lesions in ultrasonography, but they did not specify the basis of classification and the imaging evidence for each category crucial to be recognized. This condition may be the reason that it is not recognized by radiologists to date. Therefore, authenticating their value on the basis of a large group of patients with EOTs is important.

In the past few decades, the MRI of the female pelvis has gained vast acceptance by gynecologists. In the literature, the accuracy of MR imaging in distinguishing malignant from benign complex adnexal masses ranges from 83 to $93 \%$ [24-28]. This result has been proven to be superior to $\mathrm{CT}$ in the assessment of complex and indeterminate ovarian tumors due to its excellent capacity for tissue characterization [29]. However, few studies have reported the structured standards for preoperative EOTs discrimination by using MR imaging.

The results of our study demonstrated some differences in the clinical data and the MRI findings of the three groups. Clinically, MEOTs often involved elderly patients and a high proportion of postmenopausal patients than the two other groups. In the biochemical index examination, CA-125 is the most common screening and monitoring marker of EOTs, but its sensitivity and PPV are not ideal because it can be increased in some benign nonneoplastic diseases [30]. HE4 was low in patients with benign ovarian diseases but highly expressed in patients with MEOTs [31-33]. Thus, ROMA is established and studied on the basis of the CA-125 and HE4 levels and postmenopausal status [25]. In our study, MEOTs showed higher CA-125 and HE4 levels and ROMA index than BeEOTs and BEOTs, which were consistent with the results of the above reports.

In the MR imaging findings, BeEOTs usually showed oligocystic, mild enhancement, and small probability of ascites. BEOTs often presented polycystic, prominent enhancement of parenchyma component, and high probability of ascites, similar to MEOTs. However, MEOTs showed bilateral involvement [34]. This phenomenon may indicate that the tumors grow on both sides or that the tumor on one side invaded the other ovary. By quantifying the weight of some MR imaging 

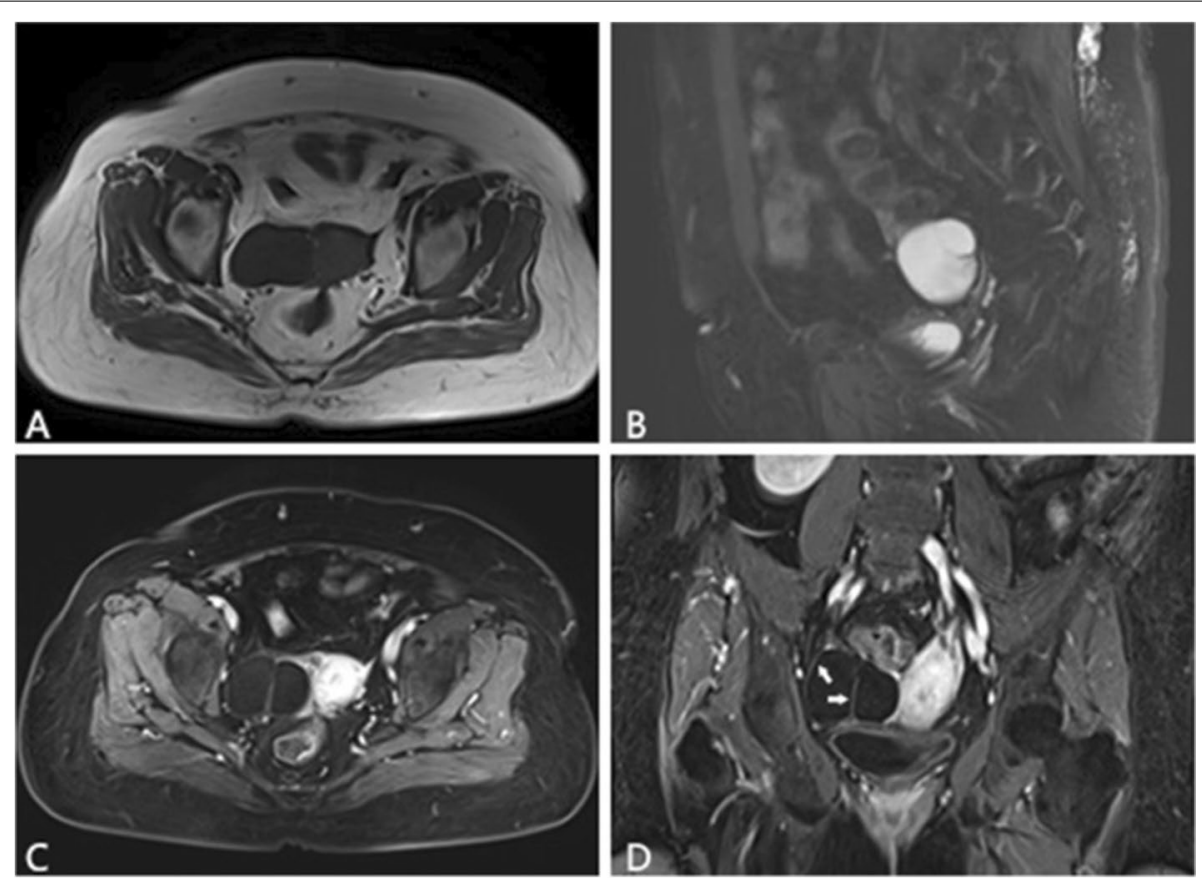

Fig. 1 A 74-year-old woman with right serous cystadenoma. A-B Tumor with few loculi shows low and high signal intensities on T1WI and T2WI, respectively. The pelvis region has no peritoneal carcinomatosis and ascite. The thin wall and septum (arrows) in contrast-enhanced T1WI (C-D) exhibit mild enhancement
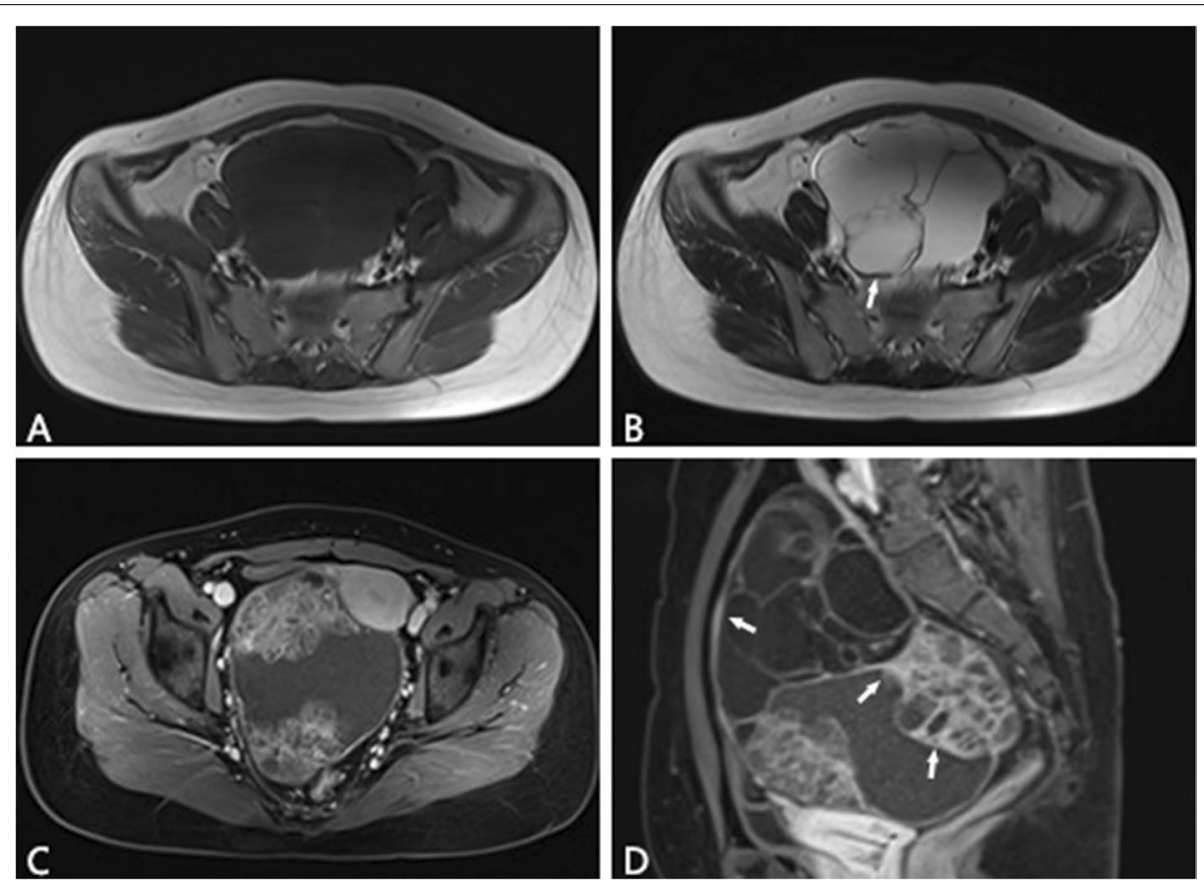

Fig. 2 A 25-year-old woman with right mucinous borderline neoplasm. A-B Multilocular cystic mass with mild thickened capsule wall on the axial T1W and T2W images in the pelvis (arrow). C-D Prominent enhancement of the unevenly thickened capsule wall and septum on axial and sagittal contrast-enhanced T1W images with FS (arrows) 

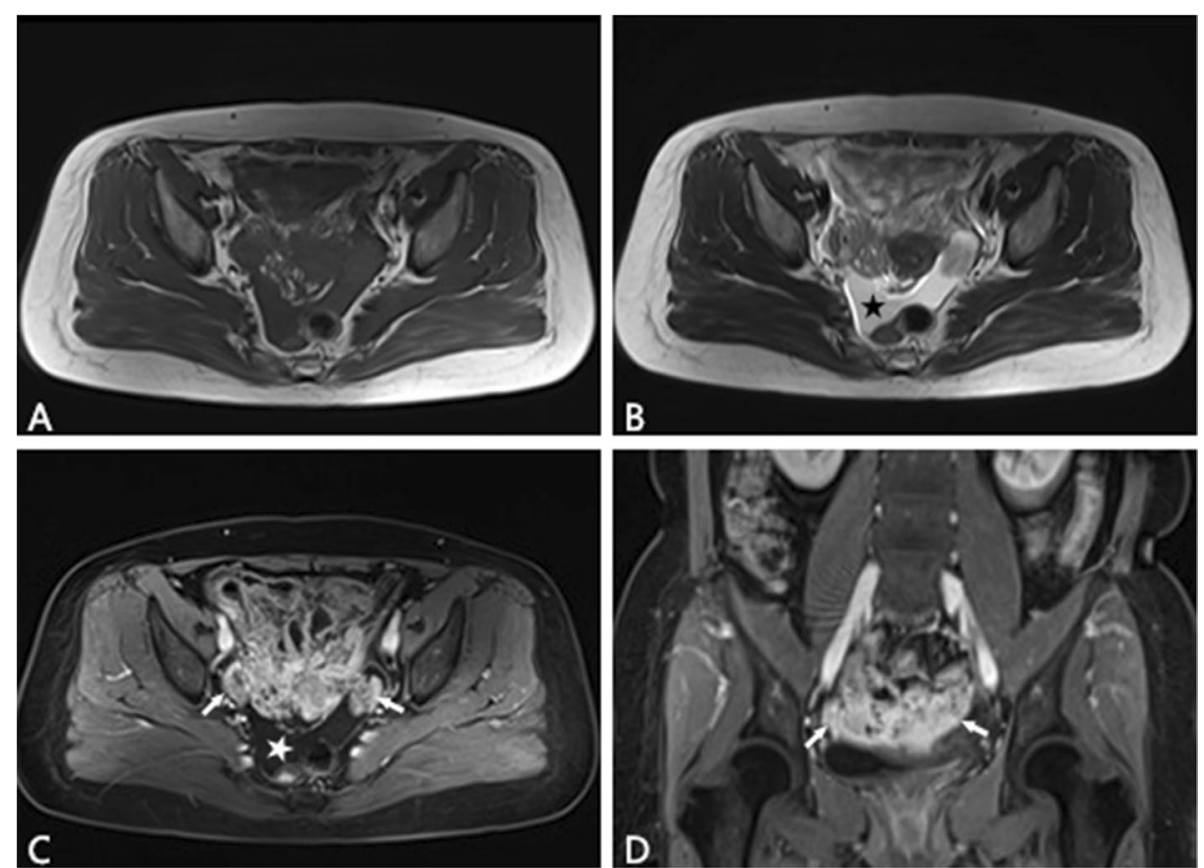

Fig. 3 A 52-year-old woman with bilateral high grade of serous ovarian carcinoma. A-B Irregular solid mass on the bilateral ovarian regions with unclear boundaries present isointensity and slight hyperintensity signals on axial T1WI and T2WI, respectively. Ascite in rectum lacuna (pentastar) was found. C-D Axial and coronary contrast-enhanced fat-suppressed T1-weighted MR image shows markedly and unevenly enhanced solid component within complex solid and follicular mass in pelvis (arrows)

Table 6 Multivariate Logistic Regression of MR imaging parameters in EOTs

\begin{tabular}{|c|c|c|c|c|c|}
\hline Covariate & $\begin{array}{l}\text { Regression } \\
\text { coefficient }\end{array}$ & Standard error & Wald & $P$ value & OR \\
\hline Age & 0.001 & 0.022 & 0.002 & 0.964 & 1.00 \\
\hline Postmenopausal & 0.851 & 0.597 & 2.029 & 0.154 & 2.34 \\
\hline Volume of tumor & 0.000 & 0.000 & 0.154 & 0.695 & 1.00 \\
\hline Volume of solid portion & -0.008 & 0.003 & 7.520 & $0.006^{*}$ & 0.99 \\
\hline Volume ratio of solid portion & 0.026 & 0.021 & 1.515 & 0.218 & 1.03 \\
\hline Maximum diameter of tumor & 0.008 & 0.056 & 0.022 & 0.883 & 1.01 \\
\hline Maximum diameter of solid portion & 0.453 & 0.218 & 4.328 & $0.038^{*}$ & 1.57 \\
\hline Maximum diameter ratio of solid portion & 0.004 & 0.024 & 0.022 & 0.883 & 1.00 \\
\hline Bilateral involvement & 1.076 & 0.881 & 1.492 & 0.222 & 2.93 \\
\hline Number of cysts & -0.236 & 0.244 & 0.930 & 0.335 & 0.79 \\
\hline Enhancement degrees & 1.289 & 0.256 & 25.275 & $0.000^{*}$ & 3.63 \\
\hline Ascites & 0.235 & 0.409 & 0.329 & 0.566 & 1.26 \\
\hline Peritoneal carcinomatosis & 3.039 & 1.191 & 6.507 & $0.011^{*}$ & 20.88 \\
\hline
\end{tabular}

*indicate a significant difference among three groups

indicators, BeEOTs usually showed thin-walled cysts and no solid component. However, BEOTs often displayed irregular thickened walls and less solid portion, and MEOTs were frequently characterized as completely solid or predominantly solid mass [35]. Thus, the three groups of EOTs had some different objective characteristics on MR images.

Through multivariate logistic regression analysis, four imaging indicators, namely, volume of solid portion, maximum diameter of solid portion, enhancement 
Table 7 Receiver operating characteristic analysis of MR imaging parameters

\begin{tabular}{|c|c|c|c|c|c|c|c|}
\hline & & Cut-off value & Sensitivity & Specificity & AUC & PPV(\%) & NPV(\%) \\
\hline \multirow[t]{2}{*}{ Volume of solid portion } & BeEOTs vs BEOTs & 0.2 & 46.94 & 100.00 & 0.74 & 100.00 & 61.19 \\
\hline & BEOTs vs MEOTs & 2.74 & 89.80 & 63.27 & 0.78 & 84.43 & 70.45 \\
\hline \multirow[t]{2}{*}{ Maximum diameter of solid portion } & BeEOTs vs BEOTs & 0.4 & 46.94 & 100.00 & 0.74 & 100.00 & 61.19 \\
\hline & BEOTs vs MEOTs & 2.2 & 86.73 & 67.35 & 0.76 & 85.47 & 67.35 \\
\hline \multirow[t]{2}{*}{ Enhancement degrees } & BeEOTs vs BEOTs & 1 & 65.96 & 94.44 & 0.80 & 94.12 & 68.63 \\
\hline & BEOTs vs MEOTs & 1 & 90.11 & 34.04 & 0.58 & 75.76 & 64.00 \\
\hline \multirow[t]{2}{*}{ Peritoneal carcinomatosis } & BeEOTs vs BEOTs & 0 & 2.04 & 100.00 & 0.51 & 100.00 & 45.45 \\
\hline & BEOTs vs MEOTs & 0 & 24.49 & 97.96 & 0.61 & 96.00 & 39.34 \\
\hline \multirow[t]{2}{*}{ Combination } & BeEOTs vs BEOTs & 1 & 74.47 & 94.44 & 0.85 & 94.59 & 73.91 \\
\hline & BEOTs vs MEOTs & 2 & 86.81 & 68.09 & 0.79 & 84.04 & 46.38 \\
\hline
\end{tabular}

degrees, and peritoneal carcinomatosis, were found significant in differentiating the three groups of EOTs. The enhancement of ovarian masses depends on the delivery and retention of contrast in the lesion. The vascular supply, capillary network, and leakage of contrast into the extravascular interstitial space contribute to the accumulation of contrast within the mass and great enhancement [36]. Our results showed that with the improvement of the subtype classification of ovarian tumors, increased solid components of tumors and prominent enhancement degrees were observed, which are in line with other reports [37]. The solid portion maybe had abundant tumor vascular supply [38], damaged basement membrane, and extracellular matrix. Consequently, MEOTs displayed prominent enhancement. MEOTs metastasize intra-abdominally with often numerous, superficial, small-sized lesions. This process is called peritoneal carcinomatosis. Previous literature has shown that peritoneal carcinomatosis may occur in BEOTs, but its incidence was evidently lower than that in MEOTs, which was consistent with our findings (2.0\% vs. $24.49 \%)$. Serous carcinoma, particularly high-grade serous carcinoma, often appears as peritoneal carcinomatosis [39, 40]. The underlying mechanisms of interactions between MEOTs and peritoneal cells are incompletely understood. In addition, the mechanisms that enable tumor adhesion and growth probably involve cadherin restructuring on the epithelial ovarian cancer cells, integrin-mediated adhesion, and mesothelial evasion by mechanical forces driven by integrin-ligand interactions [41].

In terms of diagnostic performance, most quantitative indicators had a satisfactory performance and acceptable sensitivity and specificity, as shown by the multivariate analysis of MR imaging findings. The AUCs of these quantitative imaging indicators except peritoneal carcinomatosis in differentiating BeEOTs from BEOTs ranged from 0.74 to 0.853 . However, the
AUCs for differentiating BEOTs and MEOTs ranged from 0.579 to 0.791 , indicating that the quantitative imaging measurement was useful for preoperative diagnosis and clinical decision-making. Therefore, this differentiation method can easily be generalized for use by all radiologists, regardless of their degree of expertise in pelvic imaging, as a means of improving report standardization.

Through the results of our study, MRI quantitative indicators provided relatively satisfactory results for the differentiation of EOTs. combined with MRI nonquantitative indicators and clinical indicators. Volume of solid portion, maximum diameter of solid portion, enhancement degrees, peritoneal carcinomatosis had high specificity in the identification of BeEOTs and BEOTs, which means that there was high probability of BeEOTs in multilocular cystic tumors with volume of solid portion less than $0.22 \mathrm{~cm} 3$, maximum diameter of solid portion less than $0.4 \mathrm{~cm}$, no peritoneal metastasis and no or mild enhancement, which were consistent with the results of the previous report [42]. Volume of solid portion, maximum diameter of solid portion, enhancement degrees had high sensitivity in the identification of BEOTs and MEOTs, which means that there was high probability of MEOTs in multilocular cystic tumors with volume of solid portion more than $2.74 \mathrm{~cm} 3$, maximum diameter of solid portion mores than $2.2 \mathrm{~cm}$ and moderate or prominent enhancement. Unfortunately, some of above indicators had high sensitivity/specificity, but specificity/sensitivity was lower, When that happened, combination provided satisfactory sensitivity and specificity, which is integration of MRI features and clinical indicators. We need to combine all of the patient's signs to provide greater accuracy in distinguishing of EOTs.

Several limitations were present in our study. First, some of the cases of pathological diagnosis were 

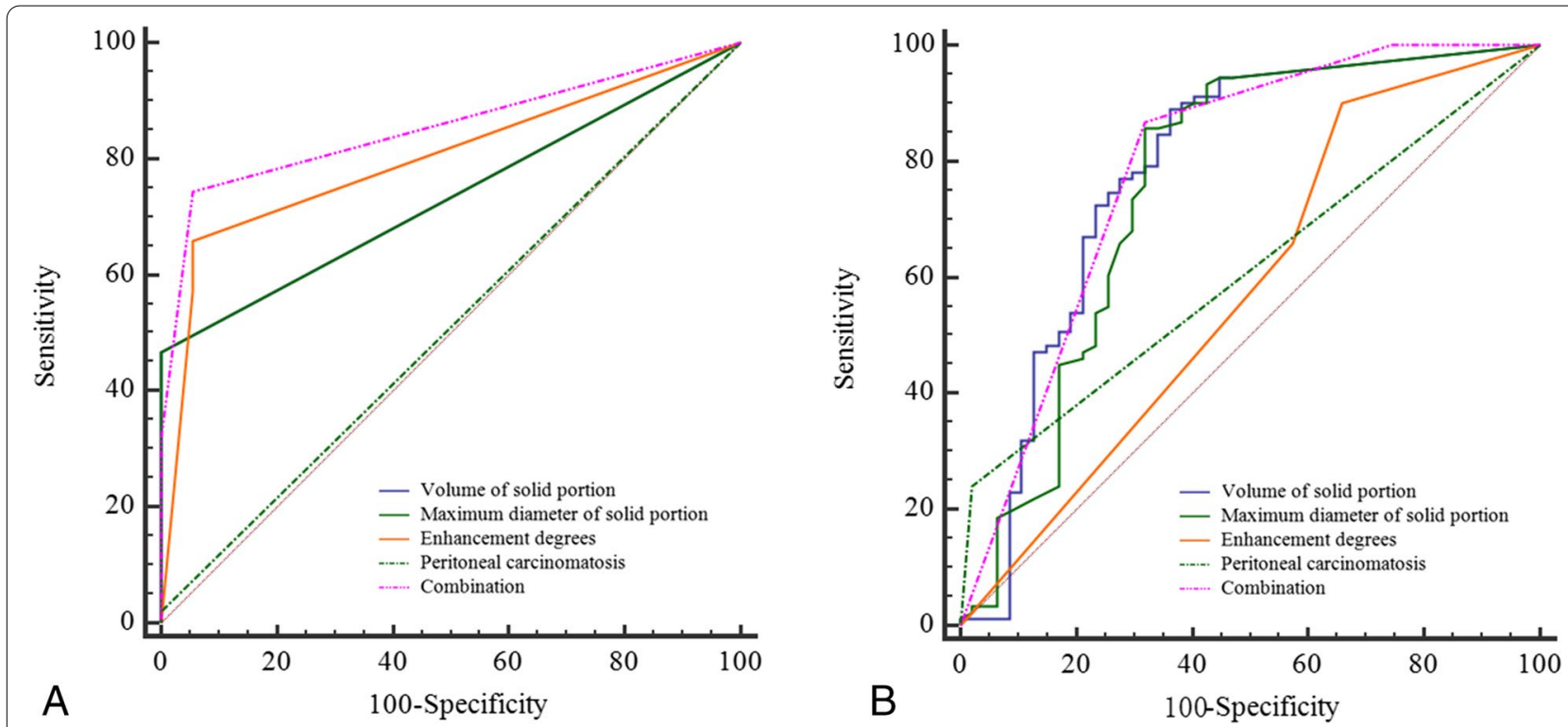

Fig. 4 Receiver operating characteristic (ROC) curve analysis of MR imaging parameters, including volume of solid portion, maximum diameter of solid portion, enhancement degrees, peritoneal carcinomatosis, and their combination for discriminating BeEOTs and BEOTs $(\mathbf{A})$ and BEOTs and MEOTs (B)

controversial. These cases included serous cystadenoma with focal borderline, which was categorized into BEOTs on the basis of the highest pathological grade. This practice narrowed the differences between the three groups or two groups to a certain extent. Thus, a detailed grouping and precise indicators on these tumors are necessary, which is crucial when deciding to opt for reasonable treatment [3-11]. Second, some cases were not performed using DW imaging and DCE-MRI in our early study. Thus, some other useful imaging features, such as ADC value and time-signal intensity curve, were not included for assessment. These factors will be considered in future research. Third, our results were based on the analysis of EOTs only and not available for other pathologic type masses, such as other types of neoplastic or non-neoplastic masses. Finally, all MR imaging examinations were performed in a single institution. The value of the indicators of these MRI features in the differentiation of three kinds of EOTs should be confirmed in a large prospective multicenter study.

In conclusion, this retrospective study has shown that the data of quantitative MR imaging indices can provide an objective basis for preoperative diagnosis and clinical decision-making. Among these indices, the volume of solid portion, maximum diameter of solid portion, enhancement degrees how good diagnostic performance. This result lay the foundation in proposing a standardized nomenclature for reporting the MRI findings of adnexal masses, which is especially useful for future artificial intelligence application in this field.

\section{Abbreviations}

EOTs: Epithelial ovarian tumors; BeEOTs: Benign epithelial ovarian tumors; BEOTs: Borderline epithelial ovarian tumors; MEOTs: Malignant epithelial ovarian tumors; ROC: Receiver-operating characteristic; CA-125: Serum carbohydrate antigen 125; HE4: Human epididymis protein 4; ROMA: Risk of ovarian malignancy algorithm; MR: Magnetic resonance; AUC: Area under the curve; TR: Repetition time; TE: Echo time; FOV: Field of view; NEX: Number of excitations; DCE-MRI: Dynamic contrast-enhanced MRI; PACS: Picture Archiving and Communication System; IOTA: International Ovarian Tumor Analysis; ICCs: Intraclass correlation coefficients; NPV: Negative predictive value; PPV: Positive predictive value; GI-RADS: Gynecologic Imaging Reporting and Data System; DWI: Diffusion Weighted Imaging; ADC: Apparent Diffusion Coefficient.

\section{Acknowledgements}

This study was supported by Shanghai Tenth People's Hospital and National Natural Science Foundation of China (81871325). The authors are grateful to all participants for their contribution to this study.

\section{Authors' contributions}

Fuxia Xiao and Lin Zhang: Participated in the whole process of this study, including designed experiment, collected data, performed the data analyses and wrote the manuscript. Sihua Yang and Kun Peng: contributed to analysis and manuscript preparation. Ting Hua: contributed to the conception of the study. Guangyu Tang: contributed significantly to experiment design and revision of manuscript. The authors read and approved the final manuscript.

\section{Funding}

This study has received funding by National Natural Science Foundation of China (81871325). 


\section{Availability of data and materials}

All data generated or analysed during this study are included in this published article.

\section{Declarations}

Ethics approval and consent to participate

Institutional Review Board approval was obtained.

\section{Consent for publication}

This retrospective study was approved by the institutional review board with the waiver of the informed consent.

\section{Competing interests}

The authors of this manuscript declare no relationships with any companies, whose products or services may be related to the subject matter of the article.

Received: 19 April 2021 Accepted: 6 September 2021

Published online: 22 January 2022

\section{References}

1. Cobb LP, Gershenson DM. Treatment of rare epithelial ovarian tumors. Hematol Oncol Clin North Am. 2018;32(6):1011-24.

2. Eskander R, Berman M, Keder L. Practice bulletin no. 174: evaluation and Management of Adnexal Masses. American College of Obstetricians and Gynecologists' committee on practice bulletins - gynecology. Obstet Gynecol. 2016;128(5):e210-26.

3. Liang F, Xu X, Liang B. Comparison of intraoperative indicators and postoperative efficacy in treatment of benign ovarian tumor: laparoscopy versus open surgery. Am J Ther. 2017;24(6):e681-8.

4. Guillaume A, Pirrello O. Preservation of fertility in surgery of benign and borderline malignant ovarian tumors. JVisc Surg. 2018;155(Suppl 1):S17-21.

5. Ozlem Dural MD, Cenk Yasa MD, Ercan Bastu MD. Laparoscopic outcomes of adnexal surgery in older children and adolescents. J Pediatr Adolesc Gynecol. 2017;30(1):128-31.

6. Oue T, Uehara S, Sasaki T. Treatment and ovarian preservation in children with ovarian tumors. J Pediatr Surg. 2015;50(12):2116-8.

7. Tomao F, Peccatori F, Del Pup L, et al. Special issues in fertility preservation for gynecologic malignancies. Crit Rev Oncol Hematol. 2016;97(January):206-19.

8. du Bois A, Trillsch F, Mahner S, Heitz F, Harter P. Management of borderline ovarian tumors. Ann Oncol. 2016;27(Suppl 1):i20-2.

9. Uzan C, Kane A, Rey A, Gouy S, Duvillard P, Morice P. Outcomes after conservative treatment of advanced-stage serous borderline tumors of the ovary. Ann Oncol. 2010;21(1):55-60.

10. Zanetta G, Rota S, Chiari S, et al. Behavior of borderline tumors with particular interest to persistence, recurrence, and progression to invasive carcinoma: a prospective study. J Clin Oncol. 2001;19:2658-64.

11. Orr B, Edwards RP. Diagnosis and treatment of ovarian cancer. Hematol Oncol Clin North Am. 2018;32(6):943-64.

12. Pujade-Lauraine E. New treatments in ovarian cancer. Ann Oncol. 2017;28(suppl_8):viii57-60.

13. Jelovac D, Armstrong DK. Recent progress in the diagnosis and treatment of ovarian cancer. Ca A Cancer J Clin. 2011;61:183-203.

14. Armbruster S, Coleman RL, Rauh-Hain JA. Management and treatment of recurrent epithelial ovarian cancer. Hematol Oncol Clin North Am. 2018;32(6):965-82.

15. Timmerman D, Valentin L, Bourne $T H$, et al. Terms, definitions and measurements to describe the sonographic features of adnexal tumors: a consensus opinion from the international ovarian tumor analysis (IOTA) group. Ultrasound Obstet Gynecol. 2000;16(5):500-5.

16. Gao MC, Lu QC, Li YS, et al. Study on hippocampal volume with quantitative 3T magnetic resonance imaging in Chinese patients with epilepsy. Chin Med J. 2012;125(18):3217-322.

17. Landis JR, Koch GG. The measurement of observer agreement for categorical data. Biometrics. 1977:33(1):159-74.
18. Shrout PE. Measurement reliability and agreement in psychiatry. Stat Methods Med Res. 1998;7(3):301-17.

19. van Nagell JR Jr, Miller RW. Evaluation and management of Itrasonographically detected ovarian tumors in asymptomatic women. Obstet Gynecol. 2016;127(5):848-58.

20. Levine D, Brown DL, Andreotti RF, Benacerraf B, Benson CB, Brewster WR, et al. Management of asymptomatic ovarian and other adnexal cysts imaged at US: Society of Radiologists in ultrasound consensus conference statement. Radiology. 2010;256:943-54.

21. Moore RG, McMeekin DS, Brown AK, et al. A novel multiple marker bioassay utilizing HE4 and CA125 for the prediction of ovarian cancer in patients with a pelvic mass. Gynecol Oncol. 2009;112(1):40-6.

22. Amor F, Vaccaro H, Alcázar JL. Gynecologic imaging reporting and data system: a new proposal for classifying adnexal masses on the basis of Sonographic findings. J Ultrasound Med. 2009;28(3):285-91.

23. Amor F, Alcázar JL, Vaccaro H, et al. GI-RADS reporting system for ultrasound evaluation of adnexal masses in clinical practice: a prospective multicenter study. Ultrasound Obstet Gynecol. 2011;38(4):450-5.

24. Lia YA, Qianga JW, Mab FH, Lia HM, Zhao SH. MRI features and score for differentiating borderline from malignant epithelial ovarian tumors. Eur J Radiol. 2018;98:136-42.

25. Kazerooni AF, Malek M. Semiquantitative dynamic contrast enhanced MRI for accurate classification of complex adnexal masses. J Magn Reson Imaging. 2017:45(2):418-27.

26. Li HM, Qiang JW, Ma FH, Zhao SH. The value of dynamic contrast-enhanced MRI in characterizing complex ovarian tumors. J Ovarian Res. 2017;10(1):4.

27. Medeiros LR, Freitas LB. Accuracy of magnetic resonance imaging in ovarian tumor: a systematic quantitative review. Am J Obstet Gynecol. 2011;204(1):67.e1-10.

28. Zhang $\mathrm{H}, \mathrm{Mao} Y$, Chen $\mathrm{X}$. Magnetic resonance imaging radiomics in categorizing ovarian masses and predicting clinical outcome: a preliminary study. Eur Radiol. 2019;29(7):3358-71.

29. Kinkel K, Lu Y, Mehdizade A, Pelte MF, Hricak H. Indeterminate ovarian mass at US: incremental value of second imaging test for characterization-metaanalysis and Bayesian analysis. Radiology. 2005;236(1):85-94.

30. Nicholson BD, Lee M-M, Wijeratne $D$, et al. Trends in cancer antigen 125 testing 2003-2014: a primary care population- based cohort study using laboratory data. Eur J Cancer Care (Engl). 2019;28(1):e12914.

31. Hellstrom I, Raycraft J, Hayden-Ledbetter M, et al. The HE4 (WFDC2) protein is a biomarker for ovarian carcinoma. Cancer Res. 2003;63(13):3695-700.

32. Drapkin $\mathrm{R}$, von Horsten $\mathrm{HH}$, Lin $\mathrm{Y}$, et al. Human epididymis protein 4 (HE4) is a secreted glycoprotein that is over expressed by serous and endometrioid ovarian carcinomas. Cancer Res. 2005;65(6):2162-9.

33. Granato T. Maria Grazia Porpora, Flavia Longo. HE4 in the differential diagnosis of ovarian masses. Clin Chim Acta. 2015;446:147-55.

34. Mukuda N, Fujii S, Inoue C, Fukunaga T, Oishi T, Harada T, et al. Bilateral ovarian tumors on MRl: how should we differentiate the lesions? Yonago Acta Med. 2018;61(2):110-6.

35. Denewar FA, Takeuchi M, Urano M, Kamishima Y, Kawai T, Takahashi N, et al. Multiparametric MRI for differentiation of borderline ovarian tumors from stage I malignant epithelial ovarian tumors using multivariate logistic regression analysis. Eur J Radiol. 2017;91:116-23.

36. Jeswani T, Padhani AR. Imaging tumour angiogenesis. Cancer Imaging. 2005;5:131-8

37. Thomassin-Naggara I, Bazot M, Daraï E, et al. Epithelial ovarian tumors: value of dynamic contrast-enhanced MR imaging and correlation with tumor angiogenesis. Radiology. 2008;248:148-59.

38. Zhao SH, Qiang JW, Zhang GF, et al. Diffusion-weighted MR imaging for dif-ferentiating borderline from malignant epithelial tumours of the ovary: pathological correlation. Eur Radiol. 2014;24:2292-9.

39. Morita H, Aoki J, Taketomi A, Sato N, Endo K. Serous Sur-face papillary carcinoma of the peritoneum: clinical, radiolog- ic, and pathologic findings in 11 patients. AJR. 2004;183:923-8.

40. Tanaka YO, Okada S, Satoh T, Matsumoto K, Oki A, Saida T, et al. Differentiation of epithelial ovarian cancer subtypes by use of imaging and clinical data: a detailed analysis. Cancer Imaging. 2016;16:3 PMID: 26873307.

41. van Baal JOAM, van Noorden CJF, Nieuwland R, Van de Vijver KK, Sturk A, van Driel WJ, et al. Development of peritoneal Carcinomatosis in epithelial ovarian cancer : a review. J Histochem Cytochem. 2018;66(2):67-83. 
42. Zhao SH, Qiang JW, Zhang GF, Wang SJ, Qiu HY, Wang L. MRl in differentiating ovarian borderline from benign mucinous cystadenoma: pathological correlation. J Magn Reson Imaging. 2014;39(1):162-6.

\section{Publisher's Note}

Springer Nature remains neutral with regard to jurisdictional claims in published maps and institutional affiliations.

- fast, convenient online submission

- thorough peer review by experienced researchers in your field

- rapid publication on acceptance

- support for research data, including large and complex data types

- gold Open Access which fosters wider collaboration and increased citations

- maximum visibility for your research: over $100 \mathrm{M}$ website views per year

At BMC, research is always in progress.

Learn more biomedcentral.com/submissions 